\title{
La respuesta de República Dominicana en épocas de covid-19: medidas implementadas
}

\section{The response of Dominican Republic in covid-19's times: implemented measures}

\section{Resposta da República Dominicana \\ na épocas do covid-19: Medidas \\ implementadas}

Autores varios*

* Aída Mary Camacho Peña, máster oficial en Hacienda Pública, Administración Financiera y Tributaria de la Universidad Nacional de Educación a Distancia (UNED) de Madrid. Funcionaria de la Administración Tributaria en República Dominicana; tutora Instituto de Estudios Fiscales de España. Miembro Grupo de Investigación Conocimientos Tributarios Latam. dcpymec18@gmail.com / https://orcid/0000-0002-4516-1866; Chaly Nicole Cruz Pozo, magíster en Derecho Administrativo de la Pontificia Universidad Católica Madre y Maestra; magíster en Derecho Público Económico del Instituto OMg. Funcionaria de la Administración Tributaria en República Dominicana. Miembro de la Red de Especialistas Tributarios y Educadores (RETRIBUYE); miembro Grupo de Investigación Conocimientos Tributarios Latam. chalycruz@gmail.com / https://orcid.org/0000-0002-0881-600k; Kelvin B. Rodríguez S., máster en Contabilidad Tributaria de la Universidad Autónoma de Santo Domingo UASD. Funcionaria de la Administración Tributaria en República Dominicana. Miembro de la Red de Especialistas Tributarios y Educadores (RETRIBUYE); miembro Grupo de Investigación Conocimientos Tributarios Latam. rodriguezkelvin22@gmail.com / https://orcid.org/00000001-9588-6104; Miguel De La Rosa, magíster en Administración Gerencial de la Universidad APEC; candidato a Doctor por la Universidad Benito Juárez (UBJ), México. Funcionario de la Administración Tributaria en República Dominicana. Miembro Grupo de Investigación Conocimientos Tributarios Latam. ang.delarosa@gmail.com / https://orcid.org/0000-0003-17923437; Yury Maycar Mejía Barros, magíster en Derecho Tributario y Especialización en Negocios Internacionales y Liderazgo Empresarial de la Universidad Complutense de Madrid. Gerente de Impuestos y Legal en la firma KPMG Américas. Miembro Grupo de Investigación Conocimientos Tributarios Latam.yurymmb@gmail.com / https://orcid.org/0000-0002-7358-4153. DOI: https://doi.org/10.18601/16926722.n18.11 


\title{
Resumen
}

Este artículo expone una visión global de las medidas implementadas en República Dominicana ante la crisis del covid-19. Detalla las iniciativas tributarias y socioeconómicas que facilitan el cumplimiento tributario y reducen los efectos negativos de la paralización económica a raíz del estado de emergencia nacional, tanto para las empresas como para los ciudadanos. Se presenta un análisis integral alusivo a prescripciones, créditos o reembolsos, cobro de impuestos, aplazamientos de pagos, control y fiscalización, plazos, recaudaciones tributarias, y trámites electrónicos. Asimismo, se estudia el efecto sobre la economía digital, factura electrónica (e-CF) y precios de transferencia. Finalmente, se revisa la propuesta de devolución de fondos de las AFP y se abordan los incentivos a sectores vulnerables, así como otras propuestas.

Palabras clave: covid-19; emergencia nacional; medidas tributarias; programas sociales; economía digital.

\begin{abstract}
This article presents a global vision of the measures implemented in the Dominican Republic in the face of the COVID-19 crisis. It details the tax and socio-economic initiatives that facilitate tax compliance and reduces the negative effects of economic paralysis as a result of the national state of emergency, for business and also citizens. A comprehensive analysis is presented, alluding to prescriptions; credits and / or refunds; tax collection; deferments of payments; control; periods; current and expected tax collections, and electronic procedures. The effect on Digital Economy, Electronic Invoice (e-CF) and Transfer Prices is also studied. Finally, it reviews the proposal for the return of funds from the AFPs, and addresses the incentives granted to vulnerable sectors, as well as other proposals of interest.
\end{abstract}

Key words: covid-19; state of emergency; tax measures; social programs; digital economy.

\section{Resumo}

Este artigo apresenta uma visão global das medidas implementadas na República Dominicana em face da crise do COVID-19. Ele detalha o conjunto de iniciativas tributárias e socioeconômicas, que facilitam a conformidade tributária e reduzem os efeitos negativos da paralisia econômica como resultado do estado nacional de emergência, para empresas quanto para cidadãos. É apresentada uma análise abrangente aludindo a prescrições, créditos e/ou reembolsos, cobranças de impostos, adiamentos de pagamentos, controle, prazo, arrecadação de impostos e os procedimentos eletrônicos. Também é 
estudado o efeito na economia digital, na fatura eletrônica (e-CF) e nos preços de transferência. Finalmente, a proposta de retorno de recursos das AFPs é revisada e aborda os incentivos concedidos a setores, assim como outras propostas de interesse

Palavras-chave: CovID-19; estado de emergência; medidas tributárias; programas sociais; economia digital.

\section{Introducción}

El Gobierno de la República Dominicana ha visto cómo la crisis producto del covid-19 ha afectado significativamente los sectores salud, economía y sociedad en general. Teniendo en cuenta esto, con el objeto de mejorar las consecuencias de la emergencia sanitaria y económica, la administración tributaria ha implementado una serie de medidas de carácter fiscal, esperando que a futuro permitan la recuperación del tejido productivo del país y del bienestar económico de los dominicanos. Igualmente, el Estado ha desarrollado programas sociales para ofrecer apoyo económico a los sectores más vulnerables.

En el presente documento exponemos cada una de las medidas implementadas en el periodo comprendido desde la declaración del estado de emergencia el 18 de marzo del 2020, hasta el 31 de mayo.

El objetivo del documento es desarrollar un análisis de las acciones desplegadas por el Ejecutivo para atacar los efectos de la pandemia en lo económico; además de las medidas estrictamente fiscales, se abordan instrumentos como la factura electrónica, los restos de la economía digital y los precios de transferencia.

\section{Prescripciones y devoluciones ${ }^{1}$}

Ante la declaración del estado de emergencia, el Ejecutivo, con el fin de garantizar los derechos de las contribuyentes y resguardar los plazos y los términos que rigen los procedimientos administrativos que se desarrollan en la Administración Tributaria, emitió por decreto la suspensión del cómputo de algunos plazos mediante el Decreto 137-20.

La suspensión del cómputo de los plazos estará vigente durante el estado de excepción, considerando dentro de este los plazos para la interposición de recursos administrativos, los plazos de prescripción y cualquier otro plazo otorgado por la Dirección General de Impuestos Internos (DGII), sobre procedimientos administrativos ya en curso.

Es importante resaltar que la suspensión de los plazos referidos no exime a los contribuyentes del cumplimiento de los deberes formales y las obligaciones tributarias, salvo disposiciones administrativas que, como se ha observado, han sido parte de las acciones tomadas. En este sentido, el Poder Judicial, mediante acta 02-2020, dispuso la suspensión de los plazos procesales.

1 Medidas consideradas hasta el 31 de mayo 2020. 
De igual forma, el Tribunal Constitucional, por el estado de emergencia, estableció mediante Resolución TC 0002/20, la suspensión de los plazos, para cualquiera de las actuaciones procesales.

Las disposiciones de suspensión de los plazos establecidos serán reanudadas tres días hábiles después del cese del estado de emergencia.

Sobre las devoluciones, hasta finales del mes de mayo 2020, dentro del marco de las medidas adoptadas por la Administración Tributaria en República Dominicana, ninguna se ha orientado a los procedimientos relacionados con las devoluciones, créditos o compensaciones de impuestos.

\section{Cobro de impuestos y aplazamientos de pago ${ }^{2}$}

Durante el tiempo de crisis por la pandemia, la Administración Tributaria ha implementado una serie de acciones encaminadas a facilitar el pago de las obligaciones fiscales de los contribuyentes, las cuales han consistido en: prórrogas en la declaración y pago, exoneraciones, diferimiento de cuotas y facilidades con acuerdos de pago. A continuación, se muestra en detalle la implementación de cada una de estas medidas.

\section{A. Aplazamientos de pago o prórrogas en las declaraciones}

Con la finalidad de ilustrar el proceso, en la tabla 1 se muestran las obligaciones fiscales que han sido prorrogadas tanto en la fecha de presentación como en el pago correspondiente producto de las medidas administrativas ejecutadas por la DGII ${ }^{3}$ a través de los avisos publicados.

\section{B. Exoneraciones de impuestos}

Dentro del marco de las medidas adoptadas tenemos las exoneraciones temporales en el pago de algunos compromisos fiscales como los anticipos correspondientes a las declaraciones de impuesto sobre la renta (ISR) de las personas jurídicas de los periodos abril, mayo y junio teniendo en cuenta que esta disposición no aplica para los grandes contribuyentes nacionales ubicados en la Gerencia de Grandes Contribuyentes de la Administración Tributaria, excepto aquellos con impedimento para operar durante el estado de emergencia ordenado por el Poder Ejecutivo mediante el Decreto 134-20 de fecha 19 de marzo de 2020. De igual manera, los anticipos de isR de las personas jurídicas.

2 Medidas consideradas hasta el 31 de mayo de 2020.

3 La DGII es el organismo encargado de administrar y recaudar los principales impuestos internos y tasas en la República Dominicana. 
Tabla 1. Obligaciones fiscales Prorrogadas

\begin{tabular}{|c|c|c|c|}
\hline Obligaciones Fiscales & Fecha límite actual & Nueva fecha límite & Prórroga en días \\
\hline ISR - Personas Jurídicas & $29 / 04 / 2020$ & $29 / 06 / 2020$ & 61 \\
\hline ISR - Personas Físicas & $30 / 03 / 2020$ & $29 / 06 / 2020$ & 91 \\
\hline 1era. Cuota Anticipo ISR PF y Sucesiones Indivisas & $30 / 06 / 2020$ & $31 / 08 / 2020$ & 62 \\
\hline 2da. Cuota Anticipo ISR PF y Sucesiones Indivisas & $30 / 09 / 2020$ & $30 / 10 / 2020$ & 30 \\
\hline 1ra. cuota ISA de Negocios Unico Dueño & $29 / 05 / 2020$ & $29 / 06 / 2020$ & 31 \\
\hline 1ra. cuota ISA de PJ con cierre dic 2019 & $29 / 05 / 2020$ & $29 / 06 / 2020$ & 31 \\
\hline 2da. cuota ISA PJ con cierre jun 2019 & $30 / 04 / 2020$ & $29 / 05 / 2020$ & 29 \\
\hline 1 era Cuota RST Ingresos PF y del Sector Agropecuario & $20 / 03 / 2020$ & $29 / 06 / 2020$ & 101 \\
\hline 1ra. cuota del RST Ingresos PJ y por compras & $31 / 03 / 2020$ & $29 / 06 / 2020$ & 90 \\
\hline 2da. cuota del RST Ingresos PJ y por compras & $30 / 06 / 2020$ & $31 / 12 / 2020$ & 184 \\
\hline 3ra. cuota del RST Ingresos PJ y por compras & $30 / 09 / 2020$ & $30 / 10 / 2020$ & 30 \\
\hline 4ta. cuota del RST Ingresos PJ y por compras & $30 / 09 / 2020$ & $31 / 12 / 2020$ & 92 \\
\hline Otras Retenciones y Retribuciones Complementarias & $13 / 04 / 2020$ & $24 / 04 / 2020$ & 11 \\
\hline Impuesto a los hidrocarburos IH4 032020 & $09 / 04 / 2020$ & $23 / 04 / 2020$ & 14 \\
\hline Contribución GLP Semanal & $09 / 04 / 2020$ & $23 / 04 / 2020$ & 14 \\
\hline Impuesto a los hidrocarburos IH1 042020 & $16 / 04 / 2020$ & $23 / 04 / 2020$ & 7 \\
\hline Contribución GLP Semanal & $16 / 04 / 2020$ & $23 / 04 / 2020$ & 7 \\
\hline Impuesto a los hidrocarburos IH2 042020 & $23 / 04 / 2020$ & $30 / 04 / 2020$ & 7 \\
\hline Contribución GLP Semanal & $23 / 04 / 2020$ & $30 / 04 / 2020$ & 7 \\
\hline Impuesto a bancas deportivas 032020 & $22 / 04 / 2020$ & $22 / 07 / 2020$ & 91 \\
\hline Impuesto a bancas de lotería 032020 & $22 / 04 / 2020$ & $22 / 07 / 2020$ & 91 \\
\hline Impuesto a bancas deportivas 042020 & $22 / 05 / 2020$ & $24 / 08 / 2020$ & 94 \\
\hline Impuesto a bancas de lotería 042020 & $22 / 05 / 2020$ & $24 / 08 / 2020$ & 94 \\
\hline Impuesto a bancas deportivas 052020 & $22 / 06 / 2020$ & $22 / 09 / 2020$ & 92 \\
\hline Impuesto a bancas de lotería 052020 & $22 / 06 / 2020$ & $22 / 09 / 2020$ & 92 \\
\hline Impuesto sobre Casinos de Juego 042020 & $05 / 05 / 2020$ & $05 / 08 / 2020$ & 92 \\
\hline Impuesto sobre máquinas tragamonedas 042020 & $05 / 05 / 2020$ & $05 / 08 / 2020$ & 92 \\
\hline Impuesto sobre Casinos de Juego 052020 & $05 / 06 / 2020$ & $07 / 09 / 2020$ & 94 \\
\hline Impuesto sobre máquinas tragamonedas 052020 & $05 / 06 / 2020$ & $07 / 09 / 2020$ & 94 \\
\hline
\end{tabular}

Fuente: elaboración propia, con base en información de Gobierno de la República Dominicana (s.f.).

En otro orden, los contribuyentes clasificados como micro y pequeñas empresas según los parámetros establecidos en la Ley 187-17 sobre el Régimen Regulatorio de las Micro, Pequeñas y Medianas Empresas (Mipymes), quedan exonerados del pago de la primera cuota del impuesto a los activos (ISA) cuyo vencimiento es el 29 de junio de 2020, así como aquellos contribuyentes con cierre fiscal 30 de junio 2020 bajo las mismas condiciones y que les corresponda el pago de la segunda cuota del ISA, cuyo vencimiento es el 29 de mayo de 2020 .

\section{Diferimiento de cuotas y acuerdos de pago}

\section{ITBIS/IVA}

Los contribuyentes recibieron la facilidad de solicitar acuerdos de pago de hasta cuatro cuotas para el impuesto sobre transferencias de bienes industrializados y servicios (ITBIS) conocido en otros países como el impuesto al valor agregado (IVA), correspondiente al periodo fiscal febrero de 2020, cuya fecha límite de declaración y pago era el 20 de marzo de 2020. Las cuotas del acuerdo de pago no estarán sujetas al interés indemnizatorio aplicado por cada mes de vigencia de este. 
Posteriormente, se dispuso de un aplazamiento hasta el viernes 24 de abril para el pago de la segunda cuota del periodo febrero y la primera cuota del periodo marzo 2020 del referido impuesto.

Se otorgó la opción de un acuerdo de pago de tres cuotas mensuales iguales y consecutivas a todos los contribuyentes del ITBIS para el periodo marzo 2020.

\section{IMPUESTO SOBRE LA RENTA}

Los contribuyentes que presenten un total a pagar podrán liquidar el ISR mediante el pago de cuatro cuotas iguales y consecutivas, las cuales no estarán sujetas al interés indemnizatorio mensual.

\section{IMPUESTO SELECTIVO AL CONSUMO}

Se otorga un acuerdo de pago de tres cuotas mensuales iguales y consecutivas a todos los contribuyentes del impuesto selectivo al consumo (ISC) de productos del alcohol y del tabaco para el periodo marzo 2020 sin interés indemnizatorio.

\section{IMPUESTO A LOS ACTIVOS}

Para el resto de los contribuyentes del ISA con fecha de cierre 31 de diciembre que no fueron beneficiados por la exención de este impuesto, el pago de la primera cuota del impuesto se efectuará mediante un acuerdo de tres cuotas iguales y consecutivas para ser pagadas en el trimestre junio-agosto del presente año. Las cuotas del acuerdo no estarán sujetas al interés indemnizatorio y serán generadas automáticamente al momento de presentar la declaración jurada del citado impuesto.

\section{Ampliación de la Vigencia EN LOS ACUERDOS DE PAGO ${ }^{4}$}

Quedan reducidas a la mitad de su valor actual las cuotas de todos los acuerdos de pago vigentes a partir del 19 de marzo de 2020, duplicando el plazo de vigencia de las cuotas pendientes de pago. Igualmente, se darán facilidades de regularización para aquellos contribuyentes que tengan cuotas atrasadas a la fecha, sin cobro de penalidades.

\section{Medidas tributarias implementadas por la Dirección General de Aduanas}

La Dirección General de Aduanas (DGA), segundo organismo recaudador más importante en República Dominicana después de la DGII, también tomó algunas medidas. Estas están dirigidas al sector industrial dominicano con la finalidad de liberar la carga tributaria de 
los contribuyentes suspendiendo temporalmente la aplicación del ITBIS/IVA a la importación de las empresas amparadas en la Ley número 392-07 sobre competitividad e innovación industrial (PROINDUSTRIA) y sus modificaciones, a los bienes que estén gravados con un $0 \%$ de arancel, con arreglo a lo dispuesto en el artículo 20 de dicha ley, no a otros bienes industriales, ni a bienes gravados con arancel o que, a causa de la aplicación de un acuerdo de libre comercio, disfruten de una preferencia arancelaria del $0 \%$.

En adición a lo anterior, se suspende temporalmente el cobro del ITBIS/IVA a las importaciones de los sectores pertenecientes a la cadena textil, confección y accesorios, pieles, fabricación de calzados de manufactura de cuero, que operan bajo la Ley 56-07, que declara de prioridad y crea un régimen nacional regulatorio para estas industrias. Las importaciones de productos, insumos y equipos médicos también fueron consideradas en la suspensión temporal del ITBIS/IVA, así como la transferencia en el mercado local; para estos fines, ambos organismos tributarios, DGII y DGA, mediante un aviso informativo, presentaron los artículos favorecidos con esta facilidad, dentro de los cuales cabe destacar los siguientes: guantes de caucho para cirugía, mascarillas de tela sin tejer, aparatos respiratorios de reanimación, termómetros de uso clínico, prendas y complementos de vestir de uso médico, entre otros.

Estas acciones demuestran la visión actual de las políticas tributarias en el país, las cuales tratan de ser lo más amigables y empáticas posibles con las circunstancias económicas que enfrentan los contribuyentes del país y el mundo, ya que de no ejecutarse tendríamos un gran porcentaje de empresas en estado de quiebra o en condiciones bastantes precarias y, en consecuencia, muchos menos pagos de tributos al Estado.

Todas estas medidas son de gran relevancia tanto para el sector privado como para el Estado, pues, al fin y al cabo, las administraciones tributarias no persiguen la desaparición de los contribuyentes, sino más bien que estos puedan cumplir sus obligaciones en la medida de sus posibilidades.

\section{Control y fiscalización ${ }^{5}$}

Las funciones de control y fiscalización en las administraciones tributarias también se han visto afectadas por la crisis del covid-19, considerando que estas siempre han requerido un contacto directo con el contribuyente, ya sea por gestiones que tengan que realizar en las oficinas de las administraciones tributarias o por las visitas que tengan que realizar a las entidades que así lo requieran.

\section{A. Fiscalizaciones}

Respecto a la función de fiscalización, tanto las notificaciones como las auditorías en proceso se han visto mermadas en un gran porcentaje, incluso muchas auditorías se han sido 
paralizado totalmente, ya que las condiciones económicas y sociales actuales no permiten su continuidad, y aquellas auditorías fiscales que han continuado lo han hecho bajo un marco operativo pasivo por las mismas circunstancias expuestas.

Es probable que en un futuro próximo únicamente los contribuyentes que no tuvieron tanto impacto negativo en esta crisis sean los principales candidatos a las fiscalizaciones, así como también aquellos que hayan aprovechado el momento de crisis para ejercer actividades económicas sin pagar los impuestos correspondientes al físco.

Es muy importante destacar que las medidas que las autoridades fiscales puedan adoptar en torno a las fiscalizaciones se comiencen a materializar a partir de mediados del año 2021, ya que en esta línea de tiempo el fisco tendrá las informaciones necesarias para hacer las verificaciones de lugar, principalmente la declaración jurada de impuesto sobre la renta del ejercicio fiscal 2020, en la cual se estaría reflejando el efecto financiero de la pandemia actual.

\section{B. Control de contribuyentes}

En la Administración Tributaria dominicana la parte operativa de control de los contribuyentes la realizan las administraciones locales, que son las oficinas locales de la DGII. Estas funcionan como puntos operativos a gran escala, responsables de recaudar los impuestos de acuerdo con lo dispuesto en el Código Tributario (Ley 11-92), y se encuentran distribuidas a nivel nacional; su función es dar seguimiento al cumplimiento fiscal del contribuyente, ofrecer asistencia e información, permitir el contacto entre los contribuyentes y la Administración Tributaria, mantener actualizados los registros de los contribuyentes bajo su jurisdicción, facilitar la liquidación y el pago de los impuestos, efectuar auditorías a las declaraciones juradas de los contribuyentes para detectar posibles inconsistencias o fraudes y brindar otros servicios requeridos por el contribuyente.

En general, como señalamos, las funciones directas de control recaen sobre estas dependencias, ofreciendo servicios como certificaciones, consultas, incorporación, modificación de datos del Registro Nacional del Contribuyente, cese de operaciones y reactivación del Registro Nacional del Contribuyente, asignación de secuencia de números de comprobantes fiscales (NCF), pagos y rectificativas de declaraciones, solicitudes, acuerdos y leyes especiales, solicitudes relacionadas con los impuestos selectivos al consumo (ISC), recepción de solicitudes de recursos de reconsideración y reclamos tributarios, solicitudes de compensaciones, reembolsos, exenciones y reintegros de impuestos y servicios relacionados con los fideicomisos e inmuebles.

Actualmente, la Administración Tributaria dominicana cuenta con 33 administraciones locales, las cuales se muestran a continuación en la figura 1.

Ante la importante función de control de estas, y frente a la amenaza representada por la pandemia del covid-19, con la finalidad de contrarrestar el efecto del distanciamiento social y, a la vez, seguir cumpliendo con el rol de facilitador, estas oficinas han continuado dando el servicio de manera remota en algún casos (la DGII publicó en su página web 


\section{Figura 1. Administraciones locales}

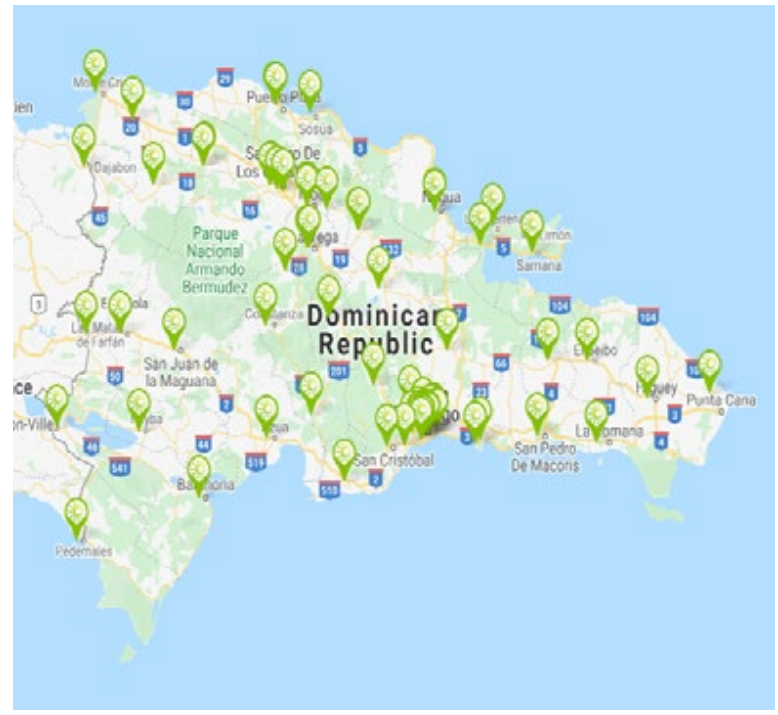

Fuente: DGII (s.f.)

los correos electrónicos de las Administraciones Locales para asistencia remota, de esta manera el contribuyente ha podido mantener el contacto sin tener que apersonarse durante el estado de emergencia). Asimismo, hay servicios que se realizan de manera presencial, con cita previa y manteniendo estrictas medidas de distanciamiento (para instruir claramente al contribuyente se publicó la Guía de prevención para la reapertura de las oficinas de DGII [2020b]).

Servicios solicitados a través del correo electrónico habilitado para las administraciones locales ${ }^{6}$ :

- Rectificativas de declaraciones juradas.

- Certificaciones sin firma digital.

- Incorporaciones al RNC.

- Modificaciones al RNC.

- Acuerdos de pago.

- Pagos a cuenta.

- Transferencias inmobiliarias.

- Pagos de hipotecas de inmuebles.

- Solicitud de exención de anticipos.

- Solicitud de pago de deudas.

6 Muchos de estos servicios se ofrecen también a través de la Oficina Virtual del contribuyente en la página web www.dgii.gov.do 
- Sucesiones y donaciones.

- Cese temporal de operaciones.

- Compensación automática de activos.

- Certificaciones de personas físicas que no posean acceso a la Oficina Virtual (OFV).

Servicios atendidos de manera presencial, mediante citas realizadas vía telefónica o correo electrónico:

- Venta de sellos para el Colegio de Abogados.

- (Ley 3-19) Recibos de la Ley 33-91.

\section{Suspensión de notificaciones de control}

De igual manera que en las notificaciones de fiscalización, las correspondientes a los casos de control han sufrido el mismo cambio, estas comunicaciones normalmente le informan al contribuyente la omisión de algún cumplimiento fiscal o la morosidad que pudiese presentar en las declaraciones de impuestos.

\section{Aplazamiento de términos para la revisión de informes y declaraciones ${ }^{7}$}

Otra de las acciones para aliviar la carga a los contribuyentes es prorrogar los plazos de presentaciones de los impuestos. Desde que fue declarado el estado de excepción, la Administración Tributaria ha emitido numerosos avisos otorgando el aplazamiento de las fechas de presentación del ITBIS, así como del ISR de personas físicas y jurídicas correspondiente al ejercicio fiscal 2019, tanto para los contribuyentes acogidos al Régimen Simplificado de Tributación (RST) como los del Régimen Ordinario.

\section{A. Aplazamientos para la presentación de declaraciones de impuestos}

Declaración jurada Contribuyentes acogidos al RST.

- La presentación de la Declaración Jurada para los contribuyentes acogidos al RST con fecha límite de presentación el 20 de marzo de 2020, fue prorrogada para el 30 de abril. Esta posteriormente fue aplazada hasta el 29 de mayo, y en una tercera prorroga se extiende hasta el 29 de junio.

Declaración de los Impuestos Sobre la Renta de Personas Físicas y Sucesiones Indivisa (IR-1). 
- La fecha de presentación era el 30 de marzo de 2019, esta fue prorrogada en tres ocasiones para el 30 de abril. Posteriormente, prorrogada hasta el 29 de mayo y luego hasta el 29 junio.

Declaración del Impuestos Sobre la Renta de Personas Jurídicas IR-2 con fecha 30 de abril

- Se prorroga hasta el 29 de mayo mediante decreto y posteriormente hasta el 29 de junio.

Declaración Informativa de Operaciones Efectuadas con Partes Relacionadas (DIOR).

- La DIOR, con fecha de cierre 30 de septiembre de 2019, la cual se presenta hasta el 30 de marzo, fue aplazada hasta el 30 de abril de 2020.

Declaración de Impuestos sobre Banca de Loterías, de Apuestas Deportivas, Casinos y Máquinas Tragamonedas.

- La declaración de estos impuestos se prorrogó por tres periodos.

Declaración de Impuestos a la Transferencia de Bienes Industrializados y Servicios (ITBIS).

- La presentación de febrero del itiBis fue aplazada del 20 hasta el 30 de marzo.

Declaración de Otras Retenciones y Retribuciones Complementarias (IR-17).

- Esta se prorroga desde 13 hasta el 24 de abril.

Declaración Jurada del Impuesto Sobre la Renta de Personas Físicas con Negocio de Único Dueño.

- Se prorroga desde el 29 de mayo hasta 29 de junio.

Declaración Jurada Informativa de las Instituciones sin Fines de Lucro con fecha de cierre 31 de diciembre.

- Se prorroga hasta el 29 de junio.

\section{La recaudación y los ingresos tributarios (durante y pospandemia) ${ }^{8}$}

El impacto de la disminución en la actividad económica y las medidas implementadas para facilitar el cumplimiento tributario empezaron a reflejarse a partir de la segunda quincena de marzo, con mayor importancia en abril.

Las medidas de prórrogas, diferimientos y acuerdos de pago representaron RD $\$ 30.300$ millones menos en los últimos dos meses, de los cuales RD\$25.627,7 millones corresponden a impuestos dejados de recaudar en abril producto de las medidas de facilitación otorgada a los contribuyentes (DGII, 2020c). 
Los ingresos del Estado por las oficinas recaudadoras se sitúan en RD\$206.958,5 millones en el periodo enero-abril 2020, lo que representa un decrecimiento de un 7,2\% con relación a igual periodo del año 2019. El cumplimiento de la meta de recaudación con relación al estimado en la Ley de Presupuesto General del Estado 2020 es de 93,4\%. Impuestos Internos recaudó el 70,2\% del total de los ingresos fiscales del periodo enero-abril 2020, mientras que la Dirección General de Aduanas aportó el 18,8\% de la recaudación y la Tesorería Nacional el 11,0\% restante (DGII, 2020c).

\section{A. Análisis de la recaudación poscovid-19}

Cual lo expuesto, las recaudaciones de la Administración Tributaria dominicana de enerabril se vieron seriamente afectadas por la caída registrada a partir de la segunda quincena de marzo y el mes de abril, consecuencia de la pandemia del covid-19 y sus efectos negativos en la actividad económica; de no haber tomado estas medidas de facilitación otorgadas por la DGII a los contribuyentes, el crecimiento del periodo enero-abril sería de 3,6\% .

La recaudación del periodo enero-abril de 2020 asciende a RD $\$ 145.239,1$ millones para la DGII, lo que representa un decrecimiento de $14,2 \%$ con respecto al mismo periodo del año anterior. Sin los ingresos no recurrentes correspondientes a enero-abril de 2019 y 2020 , la recaudación decrece $13,4 \%$.

El periodo enero-abril presenta un cumplimiento de $88,5 \%$ con relación a lo estimado. En años anteriores, el cumplimiento enero-abril fue de 100, 104 y $100 \%$ en 2017, 2018 y 2019, respectivamente (DGII, 2020c).

Como resultado del impacto de la crisis en el recaudo, para finales de año se prevé que el cumplimiento de la recaudación será de apenas $80 \%$ de la meta anual, con esto se rompe el hito logrado por la Administración Tributaria por haber alcanzado e incluso superado la meta recaudatoria durante tres años consecutivos. Sin embargo, se espera que el impacto positivo de las medidas tributarias consiga que el recaudo se vuelva eficiente.

\section{Apoyo informático electrónico para los trámites en tiempos de aislamiento preventivo ${ }^{9}$}

Desde mucho antes de la pandemia existen una serie de trámites que el contribuyente puede gestionar a través de su Oficina Virtual (OFV) en la página de la DGII, como son: la inscripción al Registro Nacional del Contribuyentes (RNC), formatos de envío de datos de declaraciones, emisión de certificaciones de inscripción/cumplimiento de deberes, solicitud de Alta de Comprobantes Fiscales, solicitud de secuencia de Números de Comprobantes Fiscales, solicitud de Solución fiscal, cambio de correo electrónico, solicitud de hidrocarburos, solicitud de autorización para la compra de alcohol, así como para su exportación e importación, Licencia de Importador Alcoholes y Tabaco Exenciones, 
solicitud de Emisión Carné de Exención de ITBIs/IVA - Zonas Franca Industriales y Servicios, entre otras.

De acuerdo con lo anterior, se podría decir que la Administración Tributaria de República Dominicana contaba ya con la preparación tecnológica para asumir esta crisis de cara a los servicios electrónicos ofrecidos al contribuyente. Sin embargo, durante este periodo se han desplegado otras facilidades, las cuales se revisarán a continuación.

\section{A. Rectificativas en línea}

Para facilitar el cumplimiento tributario ante la pandemia provocada por el covid-19, a partir del 26 del mes de mayo de 2020, fue posible la realización de las modificaciones a las declaraciones juradas a través de la Oficina Virtual (OFv), siempre que estas se encuentren dentro de la fecha hábil para su declaración, sin tener que desplazarse a las administraciones locales.

Esta facilidad está disponible para las declaraciones juradas del impuesto sobre la renta sociedades (IR2), impuesto sobre la renta personas físicas (IR1) e impuesto sobre activos (АСТ) a partir del cierre fiscal el 31 de diciembre 2019, y para el caso del ITBIS a partir del periodo fiscal mayo 2020 .

\section{B. Certificaciones digitales de inmuebles}

Adicional a otros tipos de certificaciones que podían ser generadas vía ofv, este nuevo trámite permite a las personas jurídicas propietarias de inmuebles que estén al día en el cumplimiento de sus obligaciones relacionadas con el impuesto sobre la renta (ISR) e impuesto sobre activos (ISA) generar las certificaciones de los inmuebles, sin tener que trasladarse a las oficinas.

\section{Contacto electrónico con las administraciones locales}

Otra medida implementada, como lo mencionamos en la parte alusiva al control tributario, consiste en el establecimiento de un listado de correos electrónicos por cada oficina de la Administración Tributaria, por medio los cuales los contribuyentes cuentan con la facilidad de contactar al personal que necesiten ${ }^{10}$.

\section{Nuevas opciones de actualización de datos del Registro Nacional del CONTRIBUyente (RNC)}

Con la finalidad de posibilitar al contribuyente el cumplimiento tributario indicado en el artículo 50 de la Ley 11-92 que instituye el Código Tributario de la República Dominicana, sobre los deberes formales de los contribuyentes, responsables y terceros, citamos:

Dirección General de Impuestos, RNC: 401-50625-4. 
Los contribuyentes, responsables y terceros están obligados a facilitar las tareas de determinación, fiscalización, investigación y cobranza que realice la Administración Tributaria y en especial a cumplir los deberes formales señalados a continuación: [...] e) Comunicar los cambios de domicilio, así como cualquier cambio de situación que pueda dar lugar a la alteración de la responsabilidad tributaria, dentro de los diez (10) días posteriores a la fecha en que se realicen estos cambios. (Ley 11-92.)

La Administración Tributaria ha brindado la facilidad a los contribuyentes, tanto personas físicas como jurídicas, de que puedan solicitar sus actualizaciones a los datos del Registro básico vía web, accediendo a la ofv, mediante el envío de documentos en formato digital. En esta opción, además de actualizar sus datos básicos, las sociedades pueden remitir nuevas solicitudes de cambio de accionistas, aumento/disminución de capital, adición de sucursales, entre otras.

\section{MODIFICACIÓN DECLARACIONES JURADAS}

Otra de las facilidades electrónicas, mencionada en el punto sobre las rectificaciones de las declaraciones juradas por la vía de la página web, es la modificación de declaraciones juradas.

\section{Otras dentro de la Oficina Virtual}

Como mencionamos, la Administración Tributaria, desde antes del inicio de la pandemia, tenía ya más de un $95 \%$ de sus solicitudes a disposición del contribuyente por la vía electrónica. Todo el flujo del ciclo de vida del contribuyente está respaldado por los servicios electrónicos:

- Registro o inscripción del contribuyente.

- Solicitud de las claves de acceso a la Oficina Virtual.

- Solicitud de autorización para emisión de los comprobantes fiscales.

- Solicitud y descarga de secuencias de comprobantes fiscales.

- Declaraciones de impuestos.

- Pagos y generación de autorizaciones.

- Consulta de estatus de solicitudes.

- Consulta de terceros.

- Consulta de validez de comprobantes fiscales.

- Certificaciones.

- Consultas de pagos. 


\section{Efectos del covid-19 en la economía digital a nivel local ${ }^{11}$}

El covid-19 ha planteado un desafío global, impactando de forma directa o indirecta todos los aspectos de la sociedad. Esta enfermedad ha puesto a prueba todas las formas de organización y comercio de la economía, y República Dominicana no es la excepción a esta nueva regla. Empero, conforme vamos avanzando, el impacto de la pandemia establecerá consecuencias sociales y, sobre todo, económicas; significará cambios en la cotidianidad y en el intercambio de bienes y servicios. En efecto, ya no hablaremos de cotidianidad, sino más bien de una covidianidad ${ }^{12}$.

Meses antes de desatarse esta pandemia, las empresas pequeñas, medianas e incluso grandes enfrentaban enormes desafíos respecto de su operatividad y forma de negocio y es que, dentro de un contexto globalizado e hiperconectado, era necesario hablar de una digitalización de la economía, un cambio en la forma de operar para llegar a más usuarios o impactar de manera positiva la marca. Ahora, el tema cobra mayor relevancia, pues pone en ejecución planes, diseños y planteamientos sobre su funcionalidad e imposición que se encontraban, en muchas ocasiones, en el papel.

En efecto, la propagación acelerada del covid-19 representa un reto para el desarrollo de la económica digital. La digitalización, que antes parecía un "extra" para aumentar la productividad y las ganancias, hoy se ha vuelto un requisito para que las empresas sobrevivan (Henríquez, 2020). Es que el mundo nunca cambió tan rápido y toda la economía se está modificando.

La economía digital es un desafío para los gobiernos, para las empresas y, en especial, para los ciudadanos. Y ahora, bajo esta situación actual de pandemia, significará un verdadero reto. Si no comprendemos el impacto de la transformación digital que conlleva la situación, no avanzaremos. Es una oportunidad para la mejora de la educación, los servicios públicos, los negocios y, en fin, de la calidad de vida de los ciudadanos.

\section{A. Desafíos de la economía digital}

Como es bien sabido, esta revolución de la tecnología y la transformación hacia la digitalización de operaciones, negocios y actividades ha transformado la vida en sociedad. La mayoría de las naciones pretenden impulsar la economía digital, incluidos los servicios públicos, como una forma de impulsar el progreso. La República Dominicana está, actualmente, inmersa en implementar nuevas estrategias para la reducción de la brecha digital y promover la economía digital.

Las nuevas tecnologías y la sinergia entre estas y la información traen consigo un cambio estructural tanto a nivel social como normativo. La economía digital exigirá una

11 Medidas consideradas hasta el 31 de mayo de 2020.

12 El término covidianidad, con el que se alude a los cambios en la vida cotidiana impuestos por la pandemia del covid-19, es una palabra bien formada, por lo que su uso es válido (Fundéu, 2020). 
serie de habilidades y políticas de protección social de nueva generación. Para el caso de República Dominicana supondrá un repensar de los aspectos normativos aplicables a la situación, incluyendo regular aspectos de tributación.

La llegada de la economía digital supone nuevos retos y más control. Conlleva la exigencia de controles exhaustivos respecto a seguridad de la información y facilitación del comercio; de igual forma, una mayor supervisión por parte de los entes reguladores para el caso de actividades económicas ilícitas y el cuestionamiento del concepto de privacidad (UNCTAD, 2019).

No obstante, la regulación de la economía digital es un asunto complejo, porque afecta los derechos humanos, el comercio, la creación y captura de valor económico, la aplicación de la ley y la seguridad nacional (UNCTAD, 2019). Todo esto sin mencionar el aspecto tributario que aplicaría a una actividad dentro de esta rama y la debida distribución de los beneficios. Como se afirma en el Plan de acción BEPs, la expansión de la economía digital también supone desafíos para la fiscalidad internacional (oCDE, 2014).

En ese sentido, la economía digital y las estructuras de negocios presentan los siguientes retos:

1. Atribución de beneficios.

2. Establecimiento permanente digital.

3. Atribución de riesgos.

A fin de cuentas, los desafíos que supone la economía digital deben ser abordados desde la implementación de políticas públicas, pero no de manera desagregada; ahí está la complejidad. Debe estructurarse un sistema de regulación capaz de hacer eficiente la relación de la economía digital con los demás aspectos de la cotidianidad.

\section{B. Tributación de la economía digital como consecuencia del covid-19}

La economía digital ha estado en la palestra en los últimos años como uno de los temas pendientes de consensuar. Mucho se ha discutido sobre la forma correcta de distribución de las riquezas y la tributación, pero el consenso no se ha efectuado. Entre las condicionantes tributarias de la economía digital y que ha sido punto de discusión a través de los años, están:

1. Nexo.

2. Datos.

3. Caracterización.

Sin lugar a duda, y como hemos visto con anterioridad, el covid-19 ha incrementado las transacciones digitales en todos los países, por tanto, las operaciones digitales han aumentado. En el caso de República Dominicana, el uso de internet aumentó en 12,59\% 
(INDOTEL, 2020). Evidentemente, las circunstancias actuales han cambiado el panorama y, asimismo, los servicios ofrecidos y las ventas de bienes se están ejecutando a través de nuevas tecnologías, y más ahora para evitar el contagio.

A pesar de los beneficios que ofrecen dichas plataformas y de que, efectivamente, su uso se ha visto incrementado, no existe actualmente un cambio significativo en las discusiones sobre la tributación y los desafíos en materia tributaria a consecuencia de la pandemia. No obstante, es indudable que el virus sí ha acelerado la presión para tomar una decisión sobre la forma de tributación.

\section{Pilar 1 y Pilar 2 de la ocDE}

Los proyectos Pilar I y Pilar II de la Organización para la Cooperación y el Desarrollo Económicos (OCDE) son propuestas que han sido altamente discutidas y, sobre todo, se podría decir que aceptadas. De un lado, Pilar I propone la asignación de derechos de imposición a los Estados y, por otro lado, una revisión de los aspectos de atribución de los beneficios y de la regulación del nexo (establecimiento permanente).

Pilar II, por su parte, trata de desarrollar tanto a nivel teórico como práctico la base de imposición; lo difícil siempre será llevar todo esto a la práctica y conocer las consecuencias. Cabe indicar que, bajo este precepto, se entiende que prevalece el derecho de cualquier Estado a ejercer su potestad de imposición, cuando esta no fuera ejercida por la jurisdicción primaria o el pago del impuesto fuera nulo o de bajo nivel de imposición efectiva.

A estos fines, la pandemia no ha cambiado el panorama en cuanto al fondo, sino más bien en cuanto al tiempo de decisión. Ha resultado necesario y primordial el acuerdo. Sin embargo, es necesario indicar que estos pasos exigen un gran desarrollo administrativo a nivel internacional. Asimismo, dejando un poco de lado la complejidad del tema que, dicho sea de paso, ha quedado expresa, los conceptos tanto a nivel práctico como teórico del nexo y del establecimiento permanente aún quedan pendientes por coordinar.

En fin, actualmente no hay consenso ni se conoce un producto final. Pero es evidente que, bajo esta pandemia y seguro posterior a esta, la tensión aumenta. En efecto, bajo las circunstancias actuales no es posible asegurar que se llegue a un consenso sobre la forma correcta de tributación cuando hablamos de economía digital. Sin embargo, sí es necesario afirmar que nuestro futuro será mucho más digital.

\section{Precios de transferencia en tiempo de crisis $^{13}$}

Producto de la globalización y el comercio internacional, los precios de transferencia se han convertido en un cumplimiento fiscal indispensable en la mayoría de las administraciones tributarias, por lo que sus lineamientos y regulaciones se ven afectados por la crisis. 
Han sido replanteadas las formas de realización de negocios y operaciones, asimismo el cómo regular las mismas, aplicado a todas las materias y ámbitos. Los precios de transferencia a nivel mundial y nacional no son ni serán la excepción.

A nivel administrativo, la pandemia hará y ha hecho que las empresas hagan un esfuerzo adicional sobre sus operaciones. Ha supuesto una baja en las actividades de ventas de bienes y servicios, cierre de establecimientos, paralización de actividades productivas, por lo que resultaría necesario una revisión integral y recopilación de información importante sobre, en este caso, el grupo al que pertenecen. De seguro, conllevará una modificación de las políticas internas sobre precios de transferencia que se mantenían antes de la pandemia, para ahora adaptarla a la situación actual. La información es clave en materia de precios de transferencia y lo será aún más luego de esta crisis.

Ahora bien, en adelante nos referiremos brevemente a las medidas tomadas por la Administración Tributaria en materia de precios de transferencia y que consideramos más relevantes para tener en cuenta en la materia.

- Suspensión de las tasas determinadas a través del Acuerdo de Precios Anticipados para el sector hotelero, conforme decisión tomada por Gobierno el 17 de marzo de 2020; tomando en consideración que será uno de los sectores más afectados por la pandemia actual.

- Para el cierre de este año 2020 se prevé que los ingresos por turismo se reduzcan alrededor de $30 \%$, lo que equivale a un $2,3 \%$ del producto interno bruto (PIB) (BID, 2020).

- Se estima que, actualmente, un 80 a un $90 \%$ de los trabajadores formales del sector turismo se encuentran suspendidos, lo que equivaldría a unas 288.000 a 324.000 personas (BID, 2020).

- Concesión de prórrogas para la presentación de la DIOR, con fecha de cierre 30 de septiembre, aplazando la fecha límite desde el 30 de marzo hasta el 30 de abril de 2020.

- El 29 de junio de 2020 continuó siendo la fecha límite para la presentación de la DIOR, para los contribuyentes con fecha de cierre 31 de diciembre.

Por otro lado, a mediano plazo, precios de transferencia tendrán desafíos importantes para los cuales es muy probable que los organismos internacionales que regulan su práctica (tal es el caso de la OCDE) emitan normativas para velar por el correcto cumplimiento del conocido principio de valor de mercado. Dentro de los desafíos más relevantes que se pronostican tenemos los siguientes: el manejo y búsqueda de las comparables en tiempo de la crisis, análisis y seguimiento de las operaciones financieras producidas en las multinacionales, revisiones y renegociaciones de las regulaciones en los Acuerdos de Precios Anticipados, restructuraciones económicas y operativas de las multinacionales, gastos extraordinarios intragrupo en tiempos de la crisis, evaluación de los riesgos asumibles en las multinacionales, entre otros.

Las fiscalizaciones de precios de transferencia deberán traer consigo innovaciones a fin de tener que afrontar los estudios presentados por los contribuyentes, ya que la 
situación económica actual ha llevado a muchas empresas multinacionales al cese temporal de sus operaciones arrojando disminución en los márgenes de operativos, por tanto, la comparabilidad será un elemento clave, los ajustes económicos serán realizados con mayor preponderancia como los de capital y de capacidad ociosa, estos en busca de aumentar la comparabilidad.

De igual forma, otro elemento que deberá ser observado serán las operaciones financieras intragrupo que, por posible falta de generación de flujos de efectivo de algunas de las entidades, estarán limitadas a financiar su capital de trabajo, lo cual conllevará la búsqueda financiamiento externo, principalmente con entidades del mismo grupo, o utilización de estas como garantes ante instituciones financieras.

Estas situaciones provocadas por el covid-19 traerán dificultades en la búsqueda de comparables idóneos, el uso del mejor método, y la falta de informaciones financieras para la realización de ajustes, lo que llevará a las administraciones tributarias y los contribuyentes a realizar Acuerdos de Precios Anticipados (APA), en la búsqueda de llegar a punto medio en la aplicación metodológica de algunas operaciones.

En este mismo, sentido las reestructuraciones de deudas serán otro elemento en el que muchos contribuyentes se verán inmersos, fruto de la crisis, con proveedores, entidades financieras y las propias entidades del grupo, por lo que, la disponibilidad de información será un factor relevante.

Hay muchas preguntas sin respuestas y muchas cuestiones aún bajo ponderación sobre los precios de transferencia. Es, incluso, demasiado pronto para determinar los aspectos por considerar por parte de las autoridades competentes para revisiones en esta materia. No obstante lo anterior, es válido indicar que la OCDE se encuentra elaborando una guía específica sobre cómo afrontar circunstancias extraordinarias.

\section{Factura electrónica (e-CF) $)^{14}$}

La factura electrónica en República Dominicana recibe el nombre de comprobante fiscal electrónico (e-CF) y es regulado por la DGII. El e-CF es el documento electrónico firmado digitalmente que acredita la transferencia de bienes, entrega en uso o la prestación de servicios, debiendo cumplir siempre con los requisitos establecidos en la normativa dispuesta para estos fines en República Dominicana, esto de acuerdo con el Decreto 254-06 (DGII, Norma General 01-2020, 2020).

El Decreto 254-06 es la base de los comprobantes fiscales en República Dominicana, y la Norma 06-2018, que establece las pautas para la emisión y entrega de estos. Por su parte, la Norma 05-2019 es donde aparece la figura del e-CF, ya que esta norma establece los comprobantes fiscales especiales.

Finalmente, en la Norma 01-2020, que regula la emisión y el uso de los e-CFen el proceso de facturación electrónica, se establece formalmente y se da inicio a la implementación

Medidas consideradas hasta el 31 de mayo de 2020. 
de este proceso para la República Dominicana en enero de 2020, luego de que llevara aproximadamente un año de pruebas piloto. Según el artículo 4 de la Norma citada, "los e-CF utilizados en las condiciones y supuestos establecidos en esta Norma General y sus respectivos documentos técnicos, se considerarán equivalentes a los correspondientes Comprobantes Fiscales establecidos en el Decreto núm. 254-06 o cualquier otra normativa vigente que verse sobre la materia” (DGII, Norma General 01-2020, 2020).

\section{Figura 2. Modelo de Operación del E-cF}

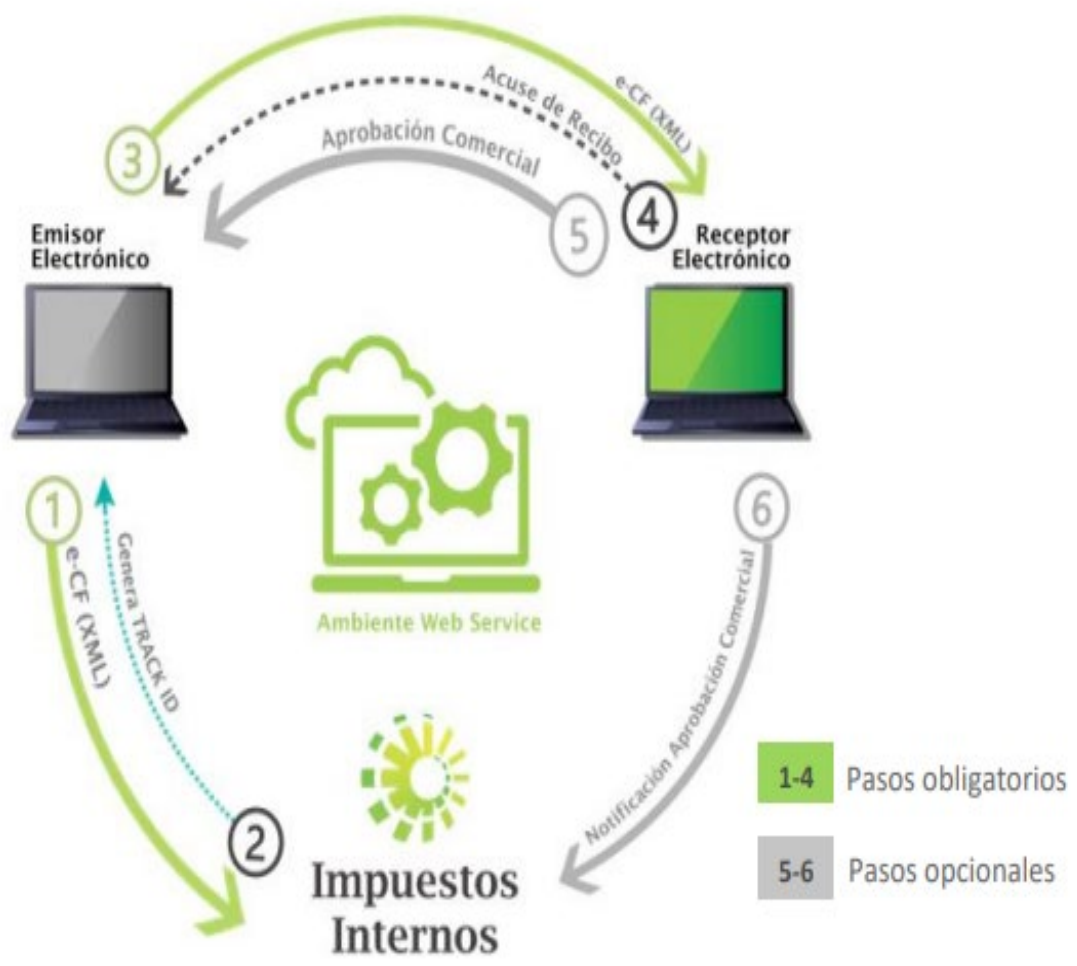

Fuente: DGII (2020d).

El modelo de operación de la e-Cf (figura 2) comprende importantes ventajas para los contribuyentes, ya que no se requiere un inventario o almacenamiento físico del documento, gastos de impresión, entrega, papel y tinta, facilidad en el manejo de la contabilidad y presentación de declaraciones y, sobre todo, supone una superioridad que en este momento crucial es una ventaja competitiva.

Se trata del descarte de la presencia física para hacer entrega de la factura, lo cual es un plus, tanto para el contribuyente como para la Administración Local. 
La facturación electrónica se ha convertido, ahora más que nunca, en una herramienta fundamental para la continuidad de los negocios, durante y pospandemia, que hace viables tanto las operaciones regulares del negocio como la facilitación del cumplimiento tributario. La anticipación de la virtualización de los servicios tributarios implica un cambio de paradigma, y, en este caso, está demostrado que durante la pandemia la emisión de los e-CF ha aumentado.

En mayo 2020, la DGI dio a conocer que: "Diez de las grandes empresas que participaron en el piloto de facturación electrónica, que concluyó en diciembre de 2019, ya son emisores de comprobantes fiscales electrónicos". Hasta el mes de mayo de 2020 se recibieron unos 10 millones de e-CF, con un tiempo de respuesta de los sistemas en la transacción de un promedio de 0,011 segundos para la recepción y 0,16 segundos para la validación, lo que ha generado un perfil productivo satisfactorio de esta innovación en la Administración Tributaria dominicana (DGII, 2020a).

Resulta interesante observar cómo precisamente en los meses de la cuarentena ha crecido la emisión de comprobantes fiscales, hecho que respalda el planteamiento sobre los beneficios de este método para los contribuyentes en medio de la crisis, por lo que el impacto en este aspecto podríamos decir que es positivo (figura 3).

\section{Figura 3. Total acumulado de COMProbantes Válidos}

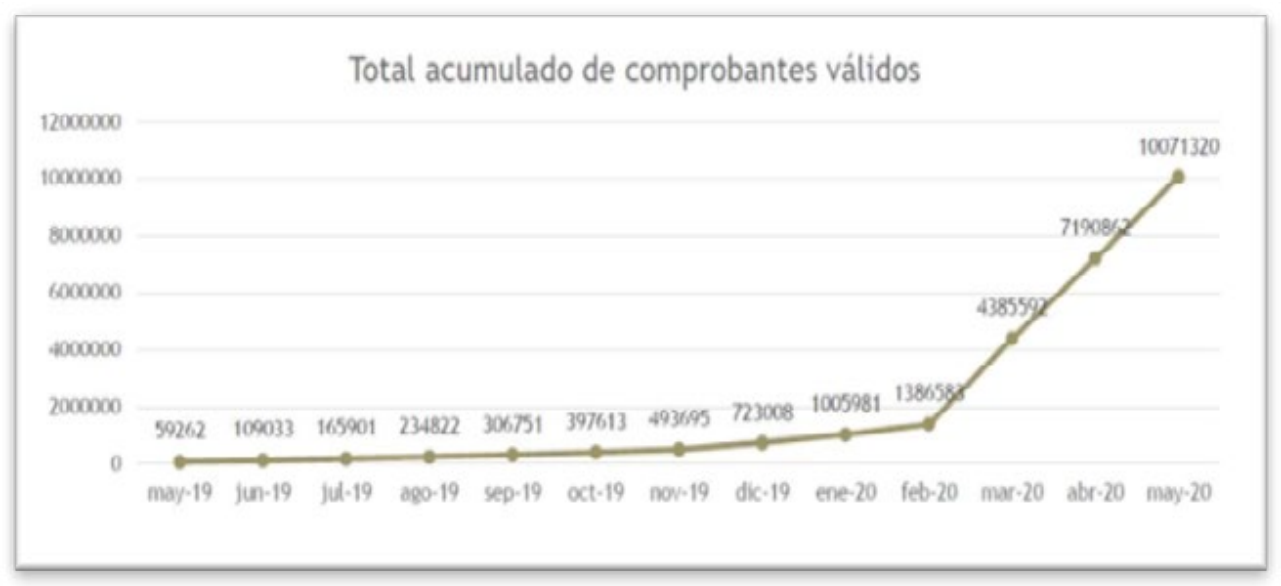

Fuente: DGII (2020a).

Lo anterior nos lleva a concluir que la factura electrónica llegó en el momento preciso para el sistema tributario dominicano, y podríamos considerarlo como uno de los servicios virtuales con mayor capacidad de garantizar la continuidad de los negocios en medio de la crisis. Su implementación fue oportuna (cuando el covid-19 aún no era considerado como amenaza en nuestro país) y en solo meses, lo que era un cambio de paradigma para 
los contribuyentes, es ahora una necesidad y una ventaja competitiva, ante al auge de la economía digital.

De igual manera, para la Administración Tributaria, las e-CF suponen una ventaja en medio de esta crisis, ya que reducen su impacto sobre la recaudación, y hacen posible las tareas de fiscalización sin necesidad de la presencia física en el domicilio fiscal. Y no podemos olvidar el aporte de estos a la economía, ya que facilitan y simplifica la cadena logística entre empresas, distribuidores y transportistas, en un momento cumbre para el e-Comerce (comercio electrónico).

En definitiva, estamos frente al mejor ejemplo de un servicio tributario cuyo sinónimo para la relación “DGII-Contribuyente-País” se traduce como "Ganar-Ganar".

\section{Propuestas sobre la mesa}

\section{A. Nuevos plazos para la repartición de beneficios de las empresas}

El pago de las bonificaciones de los trabajadores tipificadas como derechos en la participación de los beneficios de las empresas es exigible a las sociedades que logren beneficios en el ejercicio fiscal de que se trate, conforme lo establecido en la legislación laboral dominicana ${ }^{15}$, y tendrán que ser pagadas en el plazo de 90 a 120 días después de la fecha de cierre, de conformidad con el artículo 287 del Código Tributario ${ }^{16}$.

Con ocasión del estado de emergencia nacional que actualmente atraviesa nuestro país, a raíz de la pandemia, la DGII estableció la iniciativa de prorrogar, en principio hasta el día 29 de mayo del presente año (actualmente hasta el 29 de junio), el plazo para presentar la Declaración jurada anual de sociedades ${ }^{17}$, correspondiente al ejercicio fiscal que comprende desde el 1 de enero hasta el 31 de diciembre de 2019, para las personas jurídicas, incluyendo la flexibilidad del pago fraccionado en 4 cuotas sin penalidades.

En ese sentido, surge la incertidumbre de si como consecuencia inmediata de esta medida de la DGII podría interpretarse que igualmente quedan prorrogadas otras obligaciones. La pregunta nace a raíz de la Comunicación DGT-CL-02-2013 del Ministerio de Trabajo, de fecha 10 de enero de 2013, como consecuencia de la solicitud de un particular en la que se estableció el criterio que aplica para la extensión en el plazo en la declaración y pago del IsR de sociedades, igualmente para el plazo en el pago de la bonificación anual. Lo anterior, a la luz de lo previsto en el Código Tributario Dominicano ${ }^{18}$.

15 Artículo 223 y subsiguientes del Código de Trabajo.

16 Ley 11-92, de fecha aplicable juntamente con el artículo 40 del Reglamento 139-98, modificado por el Decreto 195-01 de 8 de febrero de 2001.

17 Declaración Jurada de Impuesto sobre la Renta (IR2 2019).

18 Artículo 329 del Código Tributario que permite, cuando a juicio de la DGII la situación lo amerita, conceder una prórroga de hasta dos meses. 
En tal sentido, se ha de aplicar al pago de la "bonificación anual" -formalmente conocida como Participación en los Beneficios de la Empresa- prevista en los artículos 223 y siguientes del Código de Trabajo, la que ciertas empresas deben pagar a sus empleados a más tardar el 29 de abril de 2020, con base en las utilidades o los beneficios netos correspondientes al ejercicio comprendido entre el 1 de enero y 31 de diciembre de 2019.

La posición del Ministerio de Trabajo ha sido que la prórroga aprobada por la DGII, de hasta 60 días para presentar la declaración jurada anual de sociedades (IR2), también extiende por igual periodo el plazo obligatorio para el pago de las bonificaciones o distribución de utilidades a los empleados.

En vista de lo anterior, se vuelve importante definir el tema de los plazos, no solo para que los ciudadanos puedan cumplir cabalmente, sino también dado el contexto económico actual, en especial para aquellos que quieran contar con cierta certeza al momento de acogerse a las prórrogas y, en especial, a los fines de la deducibilidad de estos gastos.

La regla es que el gasto en la bonificación será admitido ${ }^{19}$ en cumplimiento de las siguientes condiciones: i) el beneficiario sea empleado de la empresa, ii) el pago tendrá que ejecutarse en el plazo señalado y iii) es reportado a la Tesorería de la Seguridad Social (TSS) como otros ingresos gravados con la correspondiente retención del impuesto sobre la renta e INFOTEP ${ }^{20}$. La utilidad contable según los estados financieros auditados será la base de cálculo (CONACI, 2017).

Establecido lo anterior, actualmente existen diferentes perspectivas sobre el tema. Por un lado, quienes sostienen que la opinión, comunicación o resolución del Ministerio de Trabajo no puede o debe modificar lo que se encuentra determinado por ley, por lo que las empresas deben pagar entre sus empleados, en caso de que aplique, el $10 \%$ de las utilidades o los beneficios netos anuales a más tardar entre los 90 y 120 días del cierre del ejercicio social (Rodríguez, 2020).

Por otro lado, la postura de los que consideran que sí amerita prorrogar el pago de las bonificaciones, como resultado de la decisión de la DGII y previas opiniones del Ministerio de Trabajo. Conforme esta última, entonces se abren otros posibles escenarios tales como:

a) En adición a los 30 días otorgados por la DGII, los contribuyentes podrían ejercer el derecho de ley para invocar la prórroga de 60 días, en cuyo caso serían 90 días en total. Por lo que considerando que el estado de emergencia fue extendido por 25 días adicionales es predecible que la Administración Tributaria concedería nuevamente una prórroga masiva de 30 días adicionales.

19 El gasto que no cumpliera con las condiciones indicadas supra sería impugnado (ajustado) como una deducción no admitida con una contingencia fiscal equivalente al $27 \%$ de dicho gasto; sin embargo, este gasto genera un impuesto diferido.

20 Instituto Nacional de Formación Técnico Profesional creado por la Ley 116-80 http://www.infotep.gob.do/ index.php/sobre-nosotros/marco-legal/category/14-leyes 
b) Adicionalmente a esos 30 días otorgados por la DGII, los contribuyentes podrían ejercer el derecho para invocar la prórroga de 30 días, en cuyo caso serían 60 días en total, aplicando la misma predicción de la posible prórroga masiva de 30 días adicionales por la referida extensión de estado de emergencia (CONACI, 2017).

No obstante, es evidente que en caso de que las empresas que ya realizaron su declaración anual correspondiente al ejercicio fiscal de enero-diciembre de 2019, independiente de que no hayan aún liquidado el indicado impuesto, al no serles posible acogerse a la prórroga otorgada por la DGII hasta el 29 de mayo del presente año (ahora hasta el 29 de junio), tampoco les será posible diferir el pago de la bonificación anual, más allá del plazo original de ley, esto es, el día 29 del pasado mes de abril.

En el caso contrario, aquellas empresas que no hayan realizado su declaración anual correspondiente al ejercicio fiscal con cierre al 31 de diciembre 2019, y decidan acogerse a la prórroga concedida por la DGII para ello, podrán igualmente diferir el pago de la indicada bonificación anual hasta el 29 de junio del presente año, tal y como lo prevé el Ministerio de Trabajo en su señalada opinión, y la que ya ha sido acogida por tribunales de trabajo.

A pesar de que se trata de utilidades generadas en el año fiscal 2019 con anterioridad a la crisis del covid-19, e independientemente del año fiscal que se trate (marzo, junio, septiembre y diciembre), lo cierto es que el cierre de establecimientos como medida temporal de prevención por la pandemia, la falta de liquidez financiera, la caída del comercio y razones extraordinarias de fuerza mayor, representan algunas fuertes justificaciones que motivarían eventualmente al Ministerio de Trabajo, Ministerio de Hacienda y Administración Tributaria para conceder un tratamiento especial en el pago de las bonificaciones y derecho a la deducción fiscal.

Todavía las autoridades de gobierno y grupos empresariales no han establecido ninguna posición oficial y, por tanto, siguen vigentes las disposiciones analizadas anteriormente. Sin embargo, la DGII, a diferencia de otros países de la región que han guardado silencio sobre el tema, ha manifestado:

Ningún Gobierno estaba preparado para la situación pero que en nuestro país el empresariado puede estar tranquilo, ya que las instituciones de Gobierno que de otra manera tienen que ver con el tema, como el Ministerio de Trabajo, el Ministerio de Hacienda, DGII van a tomar las medidas necesarias para que las prórrogas no le causen un daño a las empresas, ya que el interés principal de estas es dar alivio.

Por su parte, jueces y docentes sostienen que habría que analizar opiniones respecto a que el ejercicio cerrado al 31/12 se audita posterior a esa fecha y no en ella misma. Por lo que, el plazo para la presentación del IR-2 $2^{21}$ suele ser el límite para dicha auditoría, y la prórroga surtiría efectos para ambas partes. 


\section{B. La aplicación de la Ley de Transparencia y Revalorización Patrimonial}

En vista de la situación económica que se está enfrentando en la actualidad, el Poder Ejecutivo, con la autorización del Congreso Nacional, dictó el Decreto 137-20 que establece el Estado de Emergencia, como señalamos anteriormente, en todo el territorio nacional desde el día 19 de marzo y prorrogado por tercera vez hasta el 31 del mes de mayo de 2020.

En consecuencia, las medidas dispuestas para lograr preservar la vida y la salud de los ciudadanos han afectado el curso normal de las operaciones comerciales, las labores de organismos y entidades gubernamentales y, particularmente, se han establecido medidas para aplazar el cumplimiento de obligaciones y deberes, viéndose a su vez afectada la esperada ejecución de la Ley 46-20 sobre Transparencia y Revalorización Patrimonial.

La referida Ley establece un régimen tributario especial y transitorio, creando las condiciones especiales a favor de aquellas personas físicas o jurídicas que puedan voluntariamente declarar, transparentar o revalorizar sus bienes y efectuar el pago de impuestos con una tasa reducida, permitiendo así la regularización de su patrimonio ante la Administración Tributaria (DGII).

El dilema es que a pesar de haber sido promulgada el 19 de febrero de 2020, poco antes de la propagación de la pandemia en el país, no ha podido ser ejecutada, ya que dentro de sus medidas dispone un plazo de 90 días a partir de su entrada en vigencia, a fines de que los contribuyentes puedan acogerse formalmente a los beneficios previstos en ella frente a la DGII, para lo cual y conforme a lo establecido en la propia Ley, para su aplicación corresponde a la referida institución, previamente, el deber de emitir una norma general que establezca la forma y los procedimientos para llevar a cabo la solicitud de declaración o revalorización patrimonial.

De modo que, han surgido inquietudes sobre el destino de la citada Ley, ya que el plazo de los 90 días en principio habría transcurrido. Al respecto, especialistas en la materia sostienen que existe una imposibilidad de aplicar la Ley debido a la pandemia del covid-19, que ha dado lugar la declaratoria de estado de emergencia y que, por ende, constituye un evento de fuerza mayor, por tratarse de una circunstancia imprevisible a la que tampoco es posible resistirse, lo que produce por igual alteraciones en los cómputos de los plazos.

Lo anterior pareciera tener lógica, por un lado, en el referido Decreto del Poder Ejecutivo, el cual ordena que mientras perdura el indicado estado de emergencia

... se suspende el cómputo de los plazos y términos de los procedimientos administrativos instrumentados ante los organismos públicos como los que integran la Administración Pública Central y desconcentrada, así como ante los órganos autónomos y descentralizados del Estado, incluyendo los plazos para la interposición de recursos administrativos, de prescripción y caducidad, así como cualquier plazo otorgado por estos organismos en ocasión de procedimientos administrativos en curso. 
Adicionalmente, en mediante Acta del Consejo del Poder Judicial ${ }^{22}$, se estableció "suspender los plazos procesales, registrales y administrativos para todos los organismos dependientes del Poder Judicial, reanudándose a los tres (3) días hábiles después de haber cesado el Estado de Emergencia”.

Especialistas del tema han planteado que, así como se ha producido la suspensión de los plazos mencionados, el caso de fuerza mayor pudiera de igual manera producir un efecto en cuanto al plazo para la aplicación de la Ley 46-20, ya que se entiende que imposibilita al contribuyente ejercer el derecho que le confiere esa Ley de acogerse a sus beneficios bajo estas condiciones (Morales, 2020). Así como en la palestra pública se ha debatido si la suspensión del plazo supone congelar su curso, que se reanudará cuando termine el Estado de Emergencia; dicho plazo comenzará a correr donde se había quedado.

A pesar de lo planteado anteriormente, al momento de iniciar la pandemia y las medidas del gobierno, ya existía el borrador de la Norma General para ser emitida por la DGII. En esta se prevé que el indicado plazo de 90 días comienza a partir de la publicación de la misma, lo cual, aunque pareciera contrario a lo establecido por la propia Ley 46-20, le es aún más favorable al contribuyente; pues, de ser así, el plazo no ha comenzado a correr y, por tanto, tendrá más tiempo para organizarse y someter la solicitud.

$\mathrm{Al}$ respecto, la $\mathrm{DGII}^{23}$ ha aclarado en los medios que, ante esta coyuntura, se ha decidido no publicar la norma por el momento, por lo que la aplicación de la Ley está congelada, pero ha hecho énfasis en que la gente no va a perder sus beneficios, pues la posición es mantenerlos. De esta manera, cuando pase la pandemia se hablará con el Congreso si hay que hacer una modificación.

En conclusión, la Ley no está en vigencia porque la Autoridad Fiscal Dominicana no ha emitido la norma por el momento, sin embargo, ha manifestado una posición mucho más amigable que otros países de Latinoamérica, bajo la premisa de dar tranquilidad a la población.

\section{Propuesta de devolución de porcentaje de los fondos de pensión}

Como hemos podido ver a lo largo de nuestro análisis, el impacto económico por la duración y gravedad de la crisis conlleva desafíos únicos para los Estados, en especial para países como el nuestro en vías de desarrollo, en donde se convierte en un desafío inmensurable alcanzar una efectiva gestión de los múltiples y diversos aspectos que intervienen en la salvaguarda de la continuidad de las funciones vitales de los seres humanos, las empresas, la economía nacional e incluso de las administraciones tributarias.

Ante los desafíos que actualmente enfrenta la República Dominicana a raíz del coronavirus, tales como el confinamiento, el teletrabajo, hacer frente a la gran pérdida de

22 Acta 002-2020 del Consejo del Poder Judicial de fecha 19 de marzo de 2020.

23 El director general de la DGII ha comentado en varias videoconferencias transmitidas a nivel nacional las razones coyunturales de la posposición de dicha ley. 
empleos, disminución de los ingresos para empleados privados que han tenido que ser suspendidos y la reducción o desaparición de los ingresos de los trabajadores independientes y los informales fruto del aislamiento social, el incremento de la demanda de servicios de salud y de insumos médicos primordiales, entre otros, se plantea buscar una solución frente el sistema de pensiones.

En ese tenor, al momento de la redacción de este artículo, en el Congreso Nacional se debate la aprobación de propuestas legislativas impulsadas en medidas que plantean la modificación de la Ley 87-01 que crea el Sistema Dominicano de Seguridad Social, que permitiría a los afiliados de las administradoras de fondos de pensiones (AFP) el retiro del 20 o el $30 \%$ de sus ahorros, como medidas destinadas a paliar la crisis económica generada por la pandemia.

Sin embargo, aun cuando el retiro de los aportes de los fondos de pensiones como iniciativa se ha conversado en varios países de Latinoamérica, mientras que en otros ya está siendo implementado, ha dado lugar a numerosos debates en la sociedad dominicana.

Actualmente, el artículo 59 de la citada ley prohíbe que los trabajadores puedan retirar parte de sus fondos, al establecer que solo podrán hacerlo cuando el empleado cumpla con los requisitos para su retiro (edad vs. años cotizando, lo que acontezca primero). Por tanto, para que dicha propuesta pueda ser una realidad desde el punto de vista legal, requiere la modificación, no solo de la Ley de Seguridad Social, sino también de sus reglamentos de aplicación, con la finalidad de reformar las condiciones para la disposición de estos fondos.

En este escenario, la propuesta ha adquirido gran simpatía por la población, en la medida en que cada vez crece más la inquietud de las personas que se han visto afectadas por la crisis generada por la pandemia por conocer si se les permitirá optar por el ahorro para poder sobrevivir, mantenerse o bien poner en marcha un negocio.

Entre los argumentos obvios que defienden la propuesta que modificaría la Ley del Sistema Dominicano de Seguridad Social, está el sentir de que esos trabajadores con dinero acumulado desearían tener esos fondos ahora y no que los reciba otra persona al morir el propietario.

No obstante, no solo el sector encargado de administrar y aplicar la ley ha mostrado oposición, sino también el Banco Central de la República (BCRD), ya que el director ha expresado su oposición a la modificación de la Ley y al retiro de hasta un $30 \%$ de sus ahorros por parte de los trabajadores, "por las consecuencias negativas y perversas sobre los sectores más vulnerables de la sociedad". Esta perspectiva la comparten numerosos economistas, quienes sostienen que los inconvenientes son mayores que el beneficio que pudiese generar, ante lo cual debe prevalecer la sostenibilidad del sistema a largo plazo sobre el tiempo de crisis.

La necesidad de protección de los ingresos de los ciudadanos en un panorama de paralización económica amerita ser innovadores. En Latinoamérica, algunos países han propuesto medidas que utilizan los fondos de pensiones para atender las necesidades actuales, 
estas medidas de políticas públicas van desde acciones de uso de fondos de pensiones colectivas a uso de los fondos de pensiones de manera individual.

Los gobiernos han estado recurriendo a distintos instrumentos relacionados con los sistemas de pensiones para proteger los ingresos. Sin embargo, es necesario reconocer que cada país es único y que no en todos los sistemas funcionarían igual las medidas.

Por un lado, algunos países han optado por ampliar el alcance de sus beneficios pensionales para llegar a la mayor cantidad de ciudadanos de una forma rápida. Por otro lado, los sistemas de capitalización individual están planteando el acceso parcial a los fondos de pensiones para atenuar el impacto económico que van a recibir los ciudadanos. Ya incluso países como Argentina y Costa Rica han estado propulsando la reducción de las contribuciones de los empleadores a la seguridad social como medidas para el mantenimiento de la capacidad de las economías una vez pase la crisis. Las variaciones son considerables.

La realidad es que nunca antes un momento histórico había puesto tanto en evidencia el problema de la desigualdad. En este momento de incertidumbre en el que muchas empresas y personas se volverán pobres, se hace urgente para la agenda del Estado generar apoyos económicos a nivel general para toda la población. Estas discusiones hacen necesario replantear lo que se ha estado haciendo y ser más novedosos. Aprender de la experiencia de otros Estados y, sobre todo, velar por que cualquier modificación al sistema de seguridad social sea en pro de hacerlo más eficiente y más justo.

A continuación, presentamos un breve análisis de sobre los programas de apoyo a los sectores económicos que se están implementando como producto de la crisis.

\section{Apoyo a los sectores económicos ${ }^{24}$}

En la República Dominicana se están ejecutando diversos programas de ayudas sociales, y de estos hay tres que por su enfoque y beneficiarios tienen un impacto transversal en la económica doméstica y empresarial, pues apuntan a mitigar la desigualdad social que crea la pandemia en la economía local. Estos programas son: Quédate en Casa, el Fondo de Asistencia Solidaria a Empleados (FASE) y el Programa de Asistencia al Trabajador Independiente (Pa' Ti).

El Programa Quédate en Casa tiene como fin asegurar la alimentación de aproximadamente 1,5 millones de familias, en su mayoría integradas por trabajadores informales, que han sido identificados sobre la base de la información validada por el Gabinete Social. A estas familias se le acreditarán RD $\$ 5.000,00$ mensuales, divididos en dos partidas quincenales, desde el mes de abril hasta el mes de junio de 2020 (Hacienda, 2020a).

El programa integra a 811.003 familias que en la actualidad se benefician de "Comer es primero", y 688.997 nuevos hogares, además, realiza una transferencia adicional que llega hasta RD\$7.000,00 mensuales, a aquellos hogares con algún miembro mayor de 60 años o con precondición de salud que lo haga vulnerable al Covid-19 (Hacienda, 2020a). 
El formato de la ayuda monetaria se acredita a través de la tarjeta de solidaridad a los beneficiarios de "Comer es primero", o con el número de cédula de identidad para los nuevos beneficiarios; para ello, la Administradora de Servicios Sociales (ADESS) del Gabinete Social envía un archivo al Banco de Reservas de la República Dominicana con los números de cédulas de los beneficiarios; para ello, la entidad financiera ha desarrollado un medio de pago virtual que permite identificar al beneficiario con un código de validación asociado que se habilita como monedero electrónico.

Luego, con este monedero electrónico, el beneficiario acude a los comercios de alimentos afiliados a la Red de Abastecimiento Social (RAs) para adquirir los alimentos y utensilios de limpieza en sus establecimientos.

Quédate en Casa impactará a no menos de 6 millones de dominicanos en todo el territorio nacional.

Por su parte, el Fondo de Asistencia Solidaria a Empleados (FASE) tiene el objetivo de apoyar de manera transitoria a los trabajadores formales suspendidos o con contratos de trabajo activos del sector privado (República, Decreto 143-20,2020), con una transferencia monetaria desde el mes de abril hasta el mes de junio de 2020, y está dividido en dos modalidades: FASE 1, que consiste en un aporte al trabajador formal que fue suspendido por su empresa, y FASE 2, que consiste en el aporte a trabajadores de empresas que se mantienen operando y que no han suspendido a ningún trabajador, pero cuyas ventas han disminuido como consecuencia del ciclo económico generado por la pandemia (Hacienda, 2020b).

Para los trabajadores de la FASE 1, el aporte corresponde al $70 \%$ del salario ordinario del trabajador reportado a la Tesorería de la Seguridad Social (TSS) para el mes de febrero de 2020, el cual nunca será menos de RD\$5.000 ni mayor de RD\$8.500,00 mensuales, lo que impacta a más de 754.000 familias (Hacienda, 2020b).

Para los trabajadores de la FASE 2, el aporte corresponde de RD\$5.000 mensuales.

Los aportes del Gobierno se pagan directamente a los trabajadores en sus cuentas de nómina reportadas por sus empleadores, y para los trabajadores que no tengan cuenta en una entidad de intermediación financiera se procede a la apertura de una cuenta de nómina en el Banco de Reservas de la República Dominicana a su nombre.

Para los meses de abril y mayo estaban incluidas las empresas de manufacturas y las micro, pequeñas y medianas empresas (Mipymes), excluyendo a los supermercados, colmados, farmacias y cualquier establecimiento comercial dedicado al expendio de alimentos crudos, medicamentos y productos de higiene; empresas de logística, distribución y transporte de materias primas y productos terminados para industria, agroindustria y alimentos; empresas de agricultura, ganadería y pesca; industrias de alimentos; empresas de seguridad privada; explotación de minas y canteras; almacenes de expendio de distribución de alimentos, productos farmacéuticos y agroindustriales; sector financiero, administradoras de fondo de pensiones, administradoras de riesgos laborales y sector seguros; multimedios; generadores de energía; sector salud; universidades; telecomunicaciones; 
organizaciones sin fines de lucro que ya reciben transferencias del Gobierno Central (República, Decreto 143-20, 2020).

A partir del primero de junio se incluyen nuevos sectores que podrán acogerse a cualquiera de las dos modalidades, entre estos se encuentran: las clínicas de estética, odontológicas, restaurantes, empresas de seguridad privada, veterinarias y universidades (República, Decreto 184-20, 2020).

Asimismo, una empresa podrá tener trabajadores en FASE I y FASE II simultáneamente, de manera que pueda contar con la asistencia de los fondos públicos para compensar su gasto de nómina en el periodo de reinserción en la actividad económica que inició el 20 de mayo de 2020.

Para el mes de abril, el subsidio de los programas Quédate en Casa y FASE abarcó unas 2.250.000 familias, lo cual desde la perspectiva económica es el ingreso de más de 8 millones de dominicanos.

El Programa de Asistencia al Trabajador Independiente ( $\mathrm{Pa}{ }^{\prime} \mathrm{Ti}$ ) tiene como fin apoyar durante el mes de junio a los trabajadores independientes que tengan un préstamo registrado en una entidad de intermediación financiera o un programa de financiamiento administrado por el Gobierno, a través de una transferencia monetaria no condicionada (República, Decreto 185-20,2020), el cual beneficiará a 202.405 trabajadores que no eran cotizantes de la Seguridad Social al 29 de febrero de 2020, pero que han visto reducir sus ingresos por las medidas de distanciamiento social adoptadas para frenar la propagación del coronavirus.

Este programa de apoyo es para trabajadores formalizados, pero que ejercen sus actividades de manera independiente.

Para el mes de junio se hará un pago de RD\$5.000 a la cuenta bancaria del trabajador o se procederá abrirle una cuenta en el Banco de Reservas de la República Dominicana, en caso de que no la tenga.

Para aplicar al programa, el ciudadano deberá estar identificado como trabajador independiente en una de las entidades de intermediación financiera y no ser beneficiario del programa Quédate en Casa o del Fondo de Asistencia al Empleado (FASE) (Hacienda, 2020a).

La mirada que acabamos de dar a los programas sociales que está implementando el Gobierno dominicano, sumadas al análisis sobre las medidas tributarias, tiene el objetivo de hacer una reflexión sobre lo vital de tener presente el papel de los impuestos en el bienestar social y cómo las acciones del sistema tributario deben colaborar con el mejoramiento de la economía y de la calidad de vida de los dominicanos.

\section{Conclusiones}

Según las estadísticas de la DGII recogidas a final del mes de abril, las medidas de facilitación tributaria han beneficiado a más de 85.000 personas naturales y 68.900 personas 
jurídicas, quienes se han favorecido de los aplazamientos y acuerdos de pago, según se detalla en el Informe de recaudación de enero-abril (DGII, 2020c).

Sin duda, la pandemia llegó en un momento crucial para el país, en víspera de elecciones y posibles cambios en materia fiscal. El apoyo de la Administración Tributaria ha sido vital en el respaldo no solo de los contribuyentes, sino de los ciudadanos, dado que estas medidas de facilitación también buscan sostener la recaudación para garantizar que el país siga trabajando en bien de los más desfavorecidos. Por esto, el sistema fiscal dominicano debe continuar fortaleciéndose para poder apoyar al Estado ante la inminente crisis económica que se avecina. A pesar del alivio que han significado estas medidas para los contribuyentes, es nuestro parecer que deben continuar evaluándose acciones para sostener las recaudaciones del Estado y seguir impulsando el cumplimiento tributario.

Se dice que las grandes crisis son también grandes oportunidades, y es por esto que vemos la crisis del covid-19 como un momento de oro para replantearnos como país, de forma tal que las facilidades fiscales y los programas sociales traigan como resultado un impacto positivo en la economía dominicana, que tanto lo necesita.

Temas como economía digital (con la imposición justa de las plataformas digitales); los nuevos esquemas de negocios nacientes con la crisis de salud y su regulación; el Bono Escolar Estudiando Progreso (BEEP); el tributo a la información, los incentivos tributarios (que generan inversión y fuentes de empleo), entre otros que están sobre la mesa, deben de ser evaluados con prioridad y cautela.

Se hace necesario continuar implementando políticas que fortalezcan el aparato productivo y la economía, y que, sobre todo, puedan magnificar lo ya logrado hasta ahora, impactando desde la perspectiva tributaria y social, con las decisiones que estamos abocados a tomar para la pospandemia.

\section{Referencias}

Banco Interamericano de Desarrollo (BID) (2020). El impacto del CovID-19 en las economías de la región (Centroamérica). BID.

Conferencia de las Naciones Unidas sobre Comercio y Desarrollo (UNCTAD) (2019). Informe sobre economía digital. UNCTAD.

Consejo Nacional de Consultores Impositivos (CONACI) (2017). Bonificación legal y voluntaria: participación de los empleados en los beneficios de la empresa. http:// www.conaci.com.do/mostrar_blog.php?id=13

Dirección General de Impuestos (s.f.). Maps. https://www.dgii.gov.do/getsatisfaction/ map/maps.html 
Dirección General de Impuestos (DGII) (2020a, mayo 17). DGII avanza en reforma e-CF; recibe 10 millones de comprobantes electrónicos. https://dgii.gov.do/noticias/Paginas/DGII-avanza-en-reforma-e-CF-recibe-10-millones-de-comprobantes-electronicos.aspx

Dirección General de Impuestos (DGII) (2020b). Guía de prevención para la reapertura de oficinas DGII. https://dgii.gov.do/Paginas/COVID-19.aspx

Dirección General de Impuestos (DGII) (2020c). Informe de recaudación enero-abril 2020. DGII.

Dirección General de Impuestos (DGII) (2020d). Informe técnico del Comprobante Fiscal Electrónico. https://dgii.gov.do/cicloContribuyente/facturacion/comprobantesFiscalesElectronicosE-CF/Documentacin \%20sobre\%20eCF/Informe/Informe\%20 T\%C3\%A9cnico\%20e-CF\%20v1.0.pdf

Fondo Monetario Internacional (FMI) (2019). Tributación Internacional de las Empresas. FMI.

Hacienda (2020a, abril 2). Gobierno iniciará pagos a beneficiarios del programa Quédate en Casa a partir de mañana. https://www.hacienda.gob.do/gobierno-iniciara-pagos-a-beneficiarios-del-programa-quedate-en-casa-a-partir-de-manana/

Hacienda (2020b, abril 7). Ministerio de Hacienda acredita las cuentas de 295 mil trabajadores formales a través de fase. https://www.hacienda.gob.do/ministerio-de-hacienda-acredita-las-cuentas-de-295-mil-trabajadores-formales-a-traves-de-fase/

Hacienda (2020c, mayo 20). Más de 200 mil trabajadores serán beneficiados con el programa de asistencia al trabajador independiente (Pa' Ti). https://www.hacienda.gob. do/mas-de-200-mil-trabajadores-seran-beneficiados-con-el-programa-de-asistencia-al-trabajador-independiente-pa-ti/

Henríquez, P. (2020). COvID-19: ¿Una oportunidad para la transformación digital de las pymes? https://blogs.iadb.org/innovacion/es/covid-19-oportunidad -transformacion-digital-pymes.

Instituto Dominicano de las Telecomunicaciones (INDOTEL) (2020). Indicadores estadísticos mensuales marzo 2020. INDOTEL. 
Morales, C. (2020). Posposición de la aplicación de la Ley de Transparencia y Revalorización Patrimonial 46-20 bajo la situación del covid-19. DR\&R Abogados y Consultores Fiscales. http://www.drr-law.com

Organización para la Cooperación y Desarrollo Económicos (OCDE) (2014). Cómo abordar los desafíos fiscales de la Economía Digital. OCDE

Rodríguez, M. (2020). Pago de bonificación anual- 2020. DR\&R Abogados y Consultores Fiscales. http://www.drr-law.com

\section{Normatividad}

DGII, Norma General 01-2020. Regula la emisión y el uso de los comprobantes.

Ley 11-92. Codigo tributario dominicano.

Presidencia de la República (2020). Decreto 143-20. Santo Domingo, Distrito Nacional, República Dominicana.

Presidencia de la República (2020). Decreto 184-20. Santo Domingo, Distrito Nacional, República Dominicana.

Presidencia de la República (2020). Decreto 185-20. Santo Domingo, Distrito Nacional, República Dominicana.

\section{Anexos}

\begin{tabular}{|l|l|}
\hline \multicolumn{1}{|c|}{$\begin{array}{c}\text { Cronológico de avisos sobre las facilidades } \\
\text { publicadas por la DGII }\end{array}$} & \multicolumn{1}{|c|}{ Enlace } \\
\hline Página oficial de los avisos DGII & $\begin{array}{l}\text { Https:/Dgii.Gov.Do/Publicacionesoficiales/Avisosin- } \\
\text { formativos/Paginas/Default.Aspx }\end{array}$ \\
\hline $\begin{array}{l}\text { Facilidades para el cumplimiento tributario de los con- } \\
\text { tribuyentes ante el impacto económico del coronavirus } \\
\text { (covid-19). }\end{array}$ & $\begin{array}{l}\text { Https://Dgii.Gov.Do/Publicacionesoficiales/Avisosin- } \\
\text { formativos/Documents/2020/23-20.Pdf }\end{array}$ \\
\hline $\begin{array}{l}\text { Prórroga del impuesto sobre la renta para personas físicas y } \\
\text { contribuyentes acogidos al régimen simplificado de } \\
\text { tributación }\end{array}$ & $\begin{array}{l}\text { Https://Dgii.Gov.Do/Publicacionesoficiales/Avisosin- } \\
\text { formativos/Documents/2020/21-20.Pdf }\end{array}$ \\
\hline Aplazamiento fecha límite pago de ITBIs & $\begin{array}{l}\text { Https://Dgii.Gov.Do/Publicacionesoficiales/Avisosin- } \\
\text { formativos/Documents/2020/24-20.Pdf }\end{array}$ \\
\hline Aplazamiento de los acuerdos de pago & $\begin{array}{l}\text { Https://Dgii.Gov.Do/Publicacionesoficiales/Avisosin- } \\
\text { formativos/Documents/2020/36-20.Pdf }\end{array}$ \\
\hline Exención del pago de anticipos del impuesto sobre la renta & $\begin{array}{l}\text { Https://Dgii.Gov.Do/Publicacionesoficiales/Avisosin- } \\
\text { formativos/Documents/2020/37-20.Pdf }\end{array}$ \\
\hline
\end{tabular}




\begin{tabular}{|c|c|}
\hline $\begin{array}{c}\text { Cronológico de avisos sobre las facilidades } \\
\text { publicadas por la DGII }\end{array}$ & Enlace \\
\hline $\begin{array}{l}\text { Extensión de vigencia de carné de exención de itBIS para } \\
\text { empresas de zonas francas }\end{array}$ & $\begin{array}{l}\text { Https://Dgii.Gov.Do/Publicacionesoficiales/Avisosin- } \\
\text { formativos/Documents/2020/41-20.Pdf }\end{array}$ \\
\hline $\begin{array}{l}\text { Aplazamiento de los impuestos selectivos al consumo (ISC) } \\
\text { sobre combustibles y contribución especial del gas licuado } \\
\text { de petróleo (GLP). }\end{array}$ & $\begin{array}{l}\text { Https://Dgii.Gov.Do/Publicacionesoficiales/Avisosin- } \\
\text { formativos/Documents/2020/44-20.Pdf }\end{array}$ \\
\hline $\begin{array}{l}\text { Medidas de facilitación para la presentación y pago de las } \\
\text { obligaciones tributarias de abril de } 2020 \text {. }\end{array}$ & $\begin{array}{l}\text { Https://Dgii.Gov.Do/Publicacionesoficiales/Avisosin- } \\
\text { formativos/Documents/2020/45-20.Pdf }\end{array}$ \\
\hline $\begin{array}{l}\text { Aplazamiento para remisión de formatos de envíos y pre- } \\
\text { sentación de las declaraciones juradas mensuales }\end{array}$ & $\begin{array}{l}\text { Https://Dgii.Gov.Do/Publicacionesoficiales/Avisosin- } \\
\text { formativos/Documents/2020/51-20.Pdf }\end{array}$ \\
\hline $\begin{array}{l}\text { Tasa de cambio para el tratamiento de las diferencias } \\
\text { cambiarias } \\
\text { Ejercicio fiscal cerrado al } 31 \text { de marzo de } 2020\end{array}$ & $\begin{array}{l}\text { Https://Dgii.Gov.Do/Publicacionesoficiales/Avisosin- } \\
\text { formativos/Documents/2020/52-20.Pdf }\end{array}$ \\
\hline $\begin{array}{l}\text { Suspensión temporal aplicación ITBIs materiales y equipos } \\
\text { médicos }\end{array}$ & $\begin{array}{l}\text { Https://Dgii.Gov.Do/Publicacionesoficiales/Avisosin- } \\
\text { formativos/Documents/2020/47-20.Pdf. }\end{array}$ \\
\hline Aplazamiento pago cuotas del ITBIS & $\begin{array}{l}\text { Https://Dgii.Gov.Do/Publicacionesoficiales/Avisosin- } \\
\text { formativos/Documents/2020/49-20.Pdf }\end{array}$ \\
\hline $\begin{array}{l}\text { Deducibilidad ISR aportes complementarios de los emplea- } \\
\text { dores al programa FASE }\end{array}$ & $\begin{array}{l}\text { Https://Dgii.Gov.Do/Publicacionesoficiales/Avisosin- } \\
\text { formativos/Documents/2020/48-20.Pdf }\end{array}$ \\
\hline $\begin{array}{l}\text { Certificación de inmuebles de personas jurídicas a través } \\
\text { de la Oficina Virtual }\end{array}$ & $\begin{array}{l}\text { Https://Dgii.Gov.Do/Publicacionesoficiales/Avisosin- } \\
\text { formativos/Documents/2020/50-20.Pdf }\end{array}$ \\
\hline $\begin{array}{l}\text { Aplazamiento para remisión de formatos de envíos y pre- } \\
\text { sentación de las declaraciones juradas mensuales. }\end{array}$ & $\begin{array}{l}\text { Https://Dgii.Gov.Do/Publicacionesoficiales/Avisosin- } \\
\text { formativos/Documents/2020/51-20.Pdf }\end{array}$ \\
\hline $\begin{array}{l}\text { Tasa de cambio para el tratamiento de las diferencias } \\
\text { cambiarias }\end{array}$ & $\begin{array}{l}\text { Https://Dgii.Gov.Do/Publicacionesoficiales/Avisosin- } \\
\text { formativos/Documents/2020/52-20.Pdf }\end{array}$ \\
\hline Extensión vigencia de placas de exhibición & $\begin{array}{l}\text { Https://Dgii.Gov.Do/Publicacionesoficiales/Avisosin- } \\
\text { formativos/Documents/2020/53-20.Pdf }\end{array}$ \\
\hline $\begin{array}{l}\text { Tabla de multiplicadores para el ajuste por inflación de los } \\
\text { activos de capital } \\
\text { Ejercicio fiscal cerrado al } 31 \text { de marzo de } 2020\end{array}$ & $\begin{array}{l}\text { Https://Dgii.Gov.Do/Publicacionesoficiales/Avisosin- } \\
\text { formativos/Documents/2020/54-20.Pdf }\end{array}$ \\
\hline $\begin{array}{l}\text { A los contribuyentes del impuesto sobre la renta multipli- } \\
\text { cador para el ajuste por inflación } \\
\text { Ejercicio fiscal cerrado al } 31 \text { de marzo de } 2020\end{array}$ & $\begin{array}{l}\text { Https://Dgii.Gov.Do/Publicacionesoficiales/Avisosin- } \\
\text { formativos/Documents/2020/55-20.Pdf }\end{array}$ \\
\hline $\begin{array}{l}\text { Solicitud de descargo de vehículo de motor de manera } \\
\text { digital }\end{array}$ & $\begin{array}{l}\text { Https://Dgii.Gov.Do/Publicacionesoficiales/Avisosin- } \\
\text { formativos/Documents/2020/56-20.Pdf }\end{array}$ \\
\hline $\begin{array}{l}\text { Remisión y presentación de aportes realizados a empleados } \\
\text { suspendidos }\end{array}$ & $\begin{array}{l}\text { Https://Dgii.Gov.Do/Publicacionesoficiales/Avisosin- } \\
\text { formativos/Documents/2020/57-20.Pdf }\end{array}$ \\
\hline $\begin{array}{l}\text { Presentación y pago de las obligaciones tributarias de } \\
\text { mayo } 2020\end{array}$ & $\begin{array}{l}\text { Https://Dgii.Gov.Do/Publicacionesoficiales/Avisosin- } \\
\text { formativos/Documents/2020/58-20.Pdf }\end{array}$ \\
\hline $\begin{array}{l}\text { Valor máximo para la calificación de viviendas de bajo costo } \\
(\operatorname{Rd} \$ 3,627,969.76)^{\mathrm{a}}\end{array}$ & $\begin{array}{l}\text { Https://Dgii.Gov.Do/Publicacionesoficiales/Avisosin- } \\
\text { formativos/Documents/2020/59-20.Pdf }\end{array}$ \\
\hline Facilidades del impuesto sobre activos & $\begin{array}{l}\text { Https://Dgii.Gov.Do/Publicacionesoficiales/Avisosin- } \\
\text { formativos/Documents/2020/60-20.Pdf }\end{array}$ \\
\hline $\begin{array}{l}\text { Facilidades para la presentación y pago de las obligaciones } \\
\text { relativas al impuesto sobre la renta (ISR) Y al Régimen } \\
\text { Simplificado de Tributación (RST) }\end{array}$ & $\begin{array}{l}\text { https://dgii.gov.do/publicacionesOficiales/avisosInfor- } \\
\text { mativos/Documents/2020/61-20.pdf }\end{array}$ \\
\hline
\end{tabular}

a Artículo 129, Ley 189-11 de 16 de julio de 2011, modificado por Ley 195-19 de 2 de julio de 2019. 


\begin{tabular}{|l|l|}
\hline \multicolumn{1}{|c|}{$\begin{array}{c}\text { Cronológico de avisos sobre las facilidades } \\
\text { publicadas por la DGII }\end{array}$} & \multicolumn{1}{c|}{ Enlace } \\
\hline Reapertura de oficinas de vehículos de motor & $\begin{array}{l}\text { https://dgii.gov.do/publicacionesOficiales/avisosInfor- } \\
\text { mativos/Documents/2020/62-20.pdf }\end{array}$ \\
\hline Servicios de las administraciones locales & $\begin{array}{l}\text { https://dgii.gov.do/publicacionesOficiales/avisosInfor- } \\
\text { mativos/Documents/2020/63-20.pdf }\end{array}$ \\
\hline $\begin{array}{l}\text { Reapertura de servicios presenciales en el Centro de Asis- } \\
\text { tencia al Contribuyente (CAC) y otras áreas de la sede central } \\
\text { de la DGII }\end{array}$ & $\begin{array}{l}\text { https://gii.gov.do/publicacionesOficiales/avisosInfor- } \\
\text { mativos/Documents/2020/64-20.pdf }\end{array}$ \\
\hline \begin{tabular}{l} 
Extensión vigencia de placas de exhibición \\
\multicolumn{1}{|c|}{$\begin{array}{l}\text { Modificación declaraciones juradas a través de la Oficina } \\
\text { Virtual (ofv) }\end{array}$}
\end{tabular} & $\begin{array}{l}\text { https://dgii.gov.do/publicacionesOficiales/avisosInfor- } \\
\text { mativos/Documents/2020/65-20.pdf } \\
\text { mativos/Documents/2020/66-20.pdf }\end{array}$ \\
\hline $\begin{array}{l}\text { Nuevas opciones de actualización de datos del Registro } \\
\text { Nacional del Contribuyente (RNC) }\end{array}$ & $\begin{array}{l}\text { https://dgii.gov.do/publicacionesOficiales/avisosInfor- } \\
\text { mativos/Documents/2020/67-20.pdf }\end{array}$ \\
\hline
\end{tabular}

Fecha de recepción: 24 de junio de 2020

Fecha de aprobación par 1: 08 de agosto de 2020

Fecha de aprobación par 2: 18 de julio de 2020 